\title{
Research On Data Analysis (Environmental, Social, and Economic) in the Context of Implementing the Circular Economy
}

\author{
Denis-Alexandru DRAGOMIR \\ Bucharest University of Economic Studies, Romania \\ denis.alexandru97@gmail.com
}

A circular approach in the economy means and promotes, in principle, the reusability of products and materials through different processes like recycling. refurbishment and remanufacturing. Thus, the latter is divided into categories based on their time through the cycles mentioned. To implement this system, compared to its long-lived predecessor, namely the linear perspective or model, a various number of actions and policies must be taken. The transition requires the setting of goals or targets meant for this operation. But will this result in a sustainable environment? The contribution and relationship between circular economy and sustainable development and thus to a more sustainable society is under discussion. This paper tries to analyze the concept of circular economy, describes its main principles and values, highlights the main differences in implementing these two antithetic systems - circular and linear - and gives information about the possibility of providing sustainability to the system in cause.

Keywords: Circular, linear, principles, sustainability, reusability

DOI: $10.24818 /$ issn14531305/25.4.2021.07

\section{Introduction \\ 1.1 What is circular economy $(\mathrm{CE})$ ?}

The concept of circular economy (also known as $\mathrm{CE}$ ) represents an economic system that integrates and promotes the idea of resource reusability continuously using the latter, having two main objectives: one of them is to eliminate waste as much as possible and the other is to increase the productivity of these resources. A circular system involves, concretely, repairing a broken resource, reusing it as much as possible, recycling, and remanufacturing.

The model of the circular economy is a systemic way that approaches development from an economic perspective, designed and built to supply benefits to business, the environment, and society.

The notion that refers to circularity has its deep roots both from a philosophical point of view and a historical perspective. The concepts of feedback and the existence of circular processes in the real-world date from very distant times. The latter can be divided into two subcategories (biological and technical), between which a clear distinction must be made. A biological cycle includes all the aspects of consumption, where both nutriments and all biological substances (such as wood or cotton) are designed to have high reusability: they can be reintegrated into the system through various processes, i.e., anaerobic digestion and composting, whereas technical cycles recover and restore components, products, and materials through specific and various strategies (repair, reuse, recycling, remanufacturing). Such an economy functions on few but very delimited principles. One of them would be the following: at its core, the main aim is to remove or to 'design out', if you want, misuse of resources, or waste. Products are built and optimized in such a way that encourages disassembly and reuse. This and the existence of product cycles is what separates the ideology of CE from the disposal and even ineffective reprocessing, where tremendous amounts of labor and energy are lost. Secondly, circularity introduces and emphasizes a strict contrast between the components of a product (consumable and durable, in this case). In contradistinction to the present day, the products that are meant to be consumed are composed of biological ingredients or 'nutrients' that are beneficial to the environment and can be cautiously given back to the biosphere, in a direct manner or using the concept of reprocessing. Hard matter such as computers or engines is constituted of technical parts that are not that 
good for the biosphere, like plastic and metal, which are, from the start, built in such a way that stimulates reusability. Thirdly, the energy necessary to power this cycle should be renewable by nature, again to increase system resilience and decrease resource dependence. As far as it concerns the technical nutrients, the $\mathrm{CE}$ replaces the notion of a consumer with that of a final user. This proposes a new attitude regarding the interaction between the producers and their consumers, namely based on product performance. Durable products are rented or shared whenever possible. If they are sold where are agreements or contracts which mention the fact that the respective materials or the product as a whole will be returned or reused at the end of its primary usage, therefore reassuring the re-entry in the cycle. Goods that are at the end of their primary usage lifetime will be turned by the circular economy into reusable materials or resources which will be available to others, thereby closing inefficient loops in industrial areas and bringing the waste to a minimum. It would offer a new perspective regarding the economic logic because it replaces production with sufficiency: reuse what you can reuse, recycle what cannot be reused, repair what can be repaired, remanufacture with recycled parts that cannot be repaired. Models of this type are divided into two categories that cultivate and extend the concepts of reusability, extending one's properties and functionality through repairing, upgrades, retrofits, and turning old into "new" by recycling. [1]

\subsection{Reduce, reuse, recycle.}

A circular economy has 4 main levels on which it operates: companies, policies, products, networks. First of all, we need the products to be designed, built, and optimized using clean methods, in such a way that they will be recyclable, reusable, all these factors are based on the green supply chains. Second of all, it is the companies' job to have new business models, to create public and private value. Third, networks between companies and customers need to be linked. And finally, markets need to be supported by policies, the latter encouraging, promoting, and helping them. Materials that come from the biosphere are sustainable, so they represent the key in the equation. For example, biomass can have multiple usage scenarios: chemical feedstock, products, packaging or might be turned into fuel necessary for transport electricity and heat. Plastics are materials that must be capable of reusability: i.e., polymer releases worldwide tonnes of greenhouse a year. By recycling the first, important quantities of greenhouse gas can be saved. A good example for this would-be China, which managed to save 14 million tonnes of greenhouse, the equivalent of almost 3 million cars off the road. New markets and business models emerge. There is a possibility that vehicle manufacturers will take old cars and upgrade them to run for longer. When a car reaches its end of life, its materials can be used in the fabrication of new vehicles by dismantling. Instead of purchasing cars, customers might opt for renting mobility goods and services. Worldwide, multiple countries are implementing and enforcing policies to promote and sustain a circular economy. China is trying, by law, to reduce reuse and recycle municipal waste. The Chinese government has invested a very important sum of yuan in incentives, projects, and permits that allow the industry to start and pursue activities that were previously forbidden, such as producing and selling wastewater (also known as greywater). If successful, it is estimated that these policies would have saved 32 trillion yuan (almost $14 \%$ of its projected GDP) in 2013. Brazil, India, and the United State are opting for a bottom-up approach. For example, Rede Asta, a network formed of more than 50 co-operative groups consisting of women across more than 5-10 Brazilian countries has established an online platform that helps in recovering materials from waste.

It is estimated that, at the end of 2030 , the percent of reusability must be somewhere between $60 \%$ and $70 \%$, and the landfill must be no more than $10 \%$ filled. The goal is for all plastics to be reusable and for $75 \%$ of packaging to be recycled. Laws and regulations must target, primarily, electronic and electrical waste, such as batteries and scrap vehicles. 
target electrical and electronic waste, scrap vehicles, and batteries. The market responsible for fiber and clothes is targeted by the EU, which is investing in regional innovations. Most of these circular-economy initiatives have saved materials, waste, energy, and emissions. Since 2009, Japan has managed to reduce, just in Kawasaki, by applying the circular economy principles in cement manufacturing, greenhouse-gas emissions by about 10\%-15\% (45.000 tonnes per year) and saving 275.000 tonnes of materials annually, since the year 2009. More than that, a park located in China, which is found in Liuzhou, Guangxi province, manages to save more than 2 million tonnes of $\mathrm{CO} 2$ emissions a year by using circulating materials and less energy. In Europe, the most relevant example is found in Slovenia, Ljubljana, which manages to beat the average of wastewater per head by $41 \%$ In a 2018 survey realized by the Eurobarometer, $53 \%$ of large companies and $41 \%$ of small businesses across the European Union reported having decreased costs of production by following the principles of the circular economy.; $25 \%$ percent of them have declared that their products are easy to reuse, repair, recycle. [2]

Through its complicated and diversified processes of development and evolution, the industrial economy as we know it has slowly and hardly moved beyond one base property established in the first days of industrialization: a model of "take-make-dispose(waste)" which was the main aim of resource consumption at that time. Companies use harvesting and extraction to gather all the necessary material, then use them to manufacture or produce a product, then, of course, sell it to the consumer, who then disembarrass it when it is no longer good for use. In terms of volume, 65 billion tons of raw material entered the economy in 2010 and it is expected to grow by another $25 \%$ by the end of 2020 . Even if major measures were adopted to improve the way resources are consumed and to explore new forms of energy, less thinking was directed to the process of systematically designing out material waste. In any case, any system that is based mainly on consumption rather than restorative use of the non-regenerative resources means significant, or major losses of value and produces negative consequences throughout the material chain. Also, many companies started to notice the fact that adopting a linear economic perspective represents a high exposure to risks (higher resource prices and supply disruptions). More businesses feel discombobulated when it comes to rising and less predictable prices in resource markets on the one hand, and fierce competition and stall demand on the other. Of course, the millennium represented a tipping point for the real prices of natural resources, the latter beginning to climb even further. At the same time, price volatility levels were higher in this century than in the previous one. If no action is taken to resolve this, extraction costs will continue to rise. Against this powerful enemy, leaders around the world are researching a 'better hedge' and an industrial model that manages to divide revenue from material input. We are talking, of course, about the circular economy systemic approach and the benefits it brings.

\subsection{Circular versus linear}

If we are to compare this model (a circular one) and the linear model from an antithetical point of view, we can conclude that the latter uses (or is based on) the "take-produce-waste" model. On the other hand, the former is more regenerative by concept and design and aims at progressively dividing consumption of depletable resources over time from the intrinsic growth. The activity that takes place within the circular model has healthy characteristics, one of the most important examples of this aspect being the fact that it aims to build, rebuild, sustain, and expand the general health and well-being of the system. More than that, it successfully recognizes the practicability of the economy: the latter must have effective applicability, even if we speak about the level of activity (large and small enterprises, individuals, organizations), or about the coverage (local or global). If we want to migrate to this model from a linear approach, the changes that are necessary to be made do not involve 
the process of mitigation regarding the negative effects that already exist, not even remotely. Instead of that, the decisions that need to be made must sustain and stimulate long-

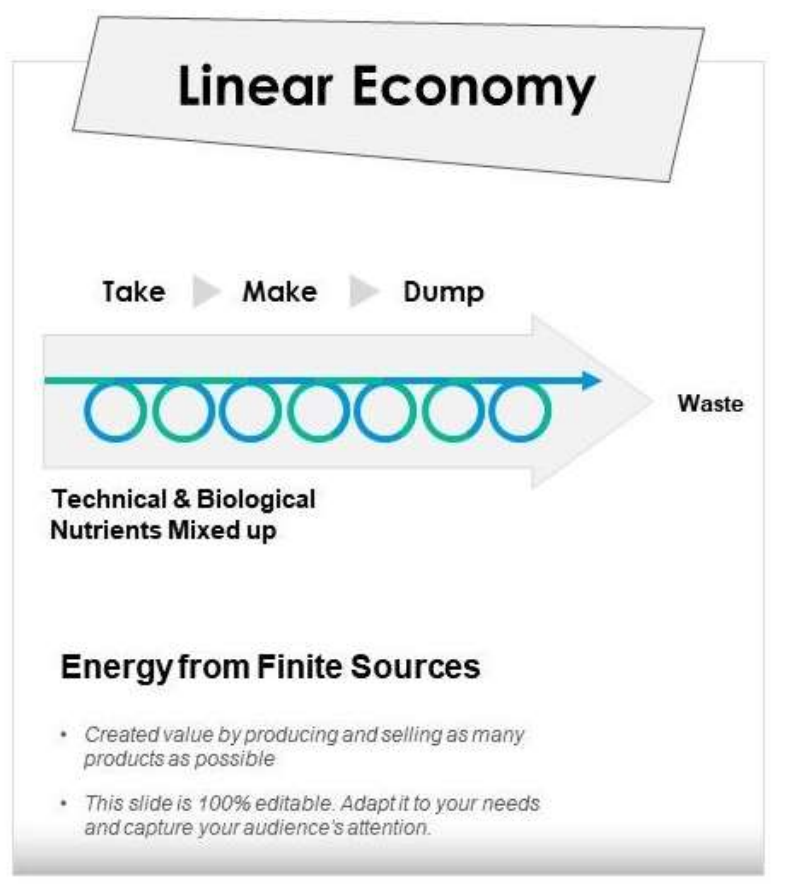

term resilience and must be able to generate various and numerous economic opportunities.

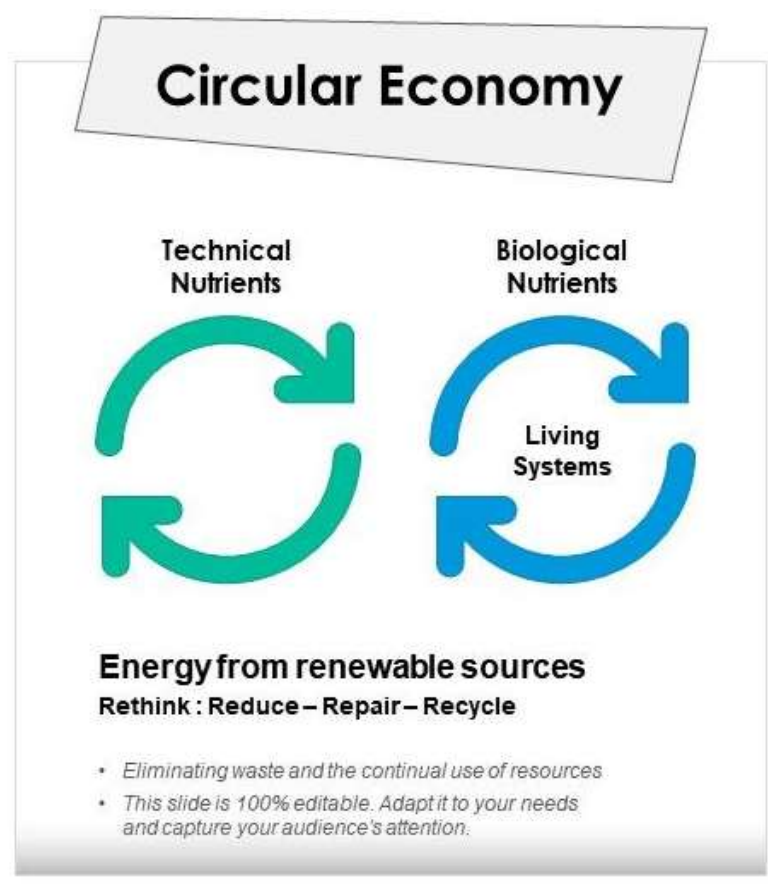

Fig. 1. Linear vs circular approaches.

Source: https://www.slideteam.net/linear-vs-circular-economy-framework.html

\subsection{Accelerating a proven concept.}

As we already know, a circular point of view represents an industrial system that is regenerative or restorative by its nature, design, and intention. It manages to replace the 'end-oflife' perspective with the one of restoration, shifting towards regenerable energy, eliminating waste using the superior design of materials, systems, products, and, of course, business models. Also, it helps reduce the use of toxic chemicals. The main principles stated above in this paper drive four clear-cut sources of value creation that offer arbitrage chances in comparison with the linear design and material usage:

1. The power of the inner circle - minimizing the comparative usage of materials in antithesis to the linear production system. It measures the capabilities of a product regarding regenerative factors. In other words, the former has a higher potential to generate savings on the shares, energy, material, and capital embedded in the product the tighter the circle is, i.e., the less the product must be changed to be reused to its fullest potential.

2. The power circling longer - maximizing the number of consecutive cycles (reuse, recycling, remanufacturing) a product passes through and the time spent in each one of them.

3. The power of cascaded use - refers to the diversification in reuse across the value chain. A good example of this would be the story of cotton clothing, which can be reused as second-hand apparel, then it is transformed into fiberfill in the furniture industry, the latter being used later in stone wool in the domain of constructions before the fibers are returned to be biosphere. In every case, the material substitutes for an entrance of virgin materials into the economy.

4. The power of pure circles - this represents uncontaminated material streams that improve the process of collection and redistribution efficiency and maintain the quality overall, especially for the technical 
area of materials, which, as a positive effect, increases productivity and extends product longevity for later use.

These four ways used to improve material productivity are not simply effects that last for a short period, being used one at a time. Their power lasts and lies in changing the run rate of required material intake. They can therefore add substantial cumulative negative effects over a classical linear system perspective. [3]

\section{Methods used.}

\subsection{Investigation.}

To be able to determine the link between sustainability and circular economy, a literature search was performed during spring 2021 using the following sources: Google, Google Scholar, and Sci-Hub. Of course, the keywords Circular economy and Sustainability were used in the title, keywords, or the abstract of the document of said research. The search resulted in a collection of both academic and non-academic literature, such as search results and various sites. Of course, articles or books where the circular economy was not the main topic were discarded, as well as screening the abstracts of said documents. For example, a document whose author said that it will contribute to the circular economy, but the main focus was a new method of recycling that would benefit the environment and the society.

The circular economy is viewed and reflected worldwide in many sources of information. Before 2012, it has been investigated mostly in the papers from Asian countries, such as China (where it was distributed the most.), due to their early adoption of the system as a national strategy. Nowadays, the development focuses all its energy and resources in Europe, which also results from all the publications. Said documents contain different definitions for the circular economy. Here are some examples:

1. an economy that has its main focus on industry in which material streams must be uncontaminated and keep circulating at a high rate, entering the biosphere only if they are nutrients [4]. An industrial economy with regenerative properties by pure intention; aims to use renewable sources of energy, eradicate waste using careful processes (such as building, designing, and optimizing a product); it provides multiple mechanisms for value creation across the value chain that are disconnected from finite material usage.

2. an activity that focuses on stock optimization. Its loop consists of four main steps, which, in turn, can be also considered as loops: repairing, remanufacturing, recycling, and reusing resources.

3. the idea is the following: if we can use and reuse products, we should do it as much as possible, instead of discarding them. So, a system is intentionally restorative by its design.

4. an alternative for the linear economy, the latter being viewed as traditional (because of the make-take-waste approach). Instead of that, the circular approach tries to keep resources in the system as much as possible, extract the maximum value from them (optimizing their efficiency, so to speak), then recover what can be recovered at the end of each cycle.

5. a term that is generally used for describing the loop stated above as the main factor for production.

6. an economy mainly based on the reusability of products and raw materials, and the regenerative attributes of natural resources used to minimize value destruction. [5]

7. it disconnects material input from revenue.

It should be noted the following aspect: the list mentioned above does not include all the possible definitions of this concept, so it is not exhaustive, as there can be many more which were not documented for the scope of this paper. However, one of the main common approaches that those seven statements seem to have been the process of maximizing the value of resources that enter through the system and trying to reduce waste to a minimum. This principle can be traced to many economic concepts. For example:

- the cradle-to-cradle concept

- the limits to growth concept - an experi- 
ment was conducted, in which three scenarios were applied, using computer simulation for exponential economic and human resource growth under limited resources. Two of them collapsed, whereas the third lead to a stabilized world

- the steady-state economy

- the spaceman economy - replacing open economic systems with a cyclical one, capable of continuous reproduction of materials. There was a problem, though, as such a system cannot exist without energy entering the system

- the industrial ecology - suggests industrial emphasis in biological ecosystems, the energy being only external input

Another common principle that has been extracted from these definitions is represented by eco-efficiency. This can play various roles in a circular economy, depending on the context. Some view it as a purpose, some can take this too far and make those two concepts synonymous and some have a more realistic point of view: they view it as one of the many consequences of implementing and maintaining a circular system in the economy. This is said because $\mathrm{CE}$ focuses mainly on job and value creation through the reduction of material waste and also decreasing the price volatility of said materials.

Another common aspect shared by the statements made above is represented by achieving its purpose using a cycle which includes, as stated earlier in this paper, the four main environmental strategies (or the four main Rs, if you want): Reduce, Reuse, Recycle, Repair (Recover, as stated by other sources) [6]. So, $\mathrm{CE}$ is being given a generic connotation, which main focus is reducing, reusing, and recycling. There is also another meaning for those 4 Rs - Refuse, Repair, Refurbish Remanufacture being one of them.

As for the final similarity, we can speak about the waste prevention that is being mentioned and promoted in the system. In some definitions, this is viewed as the main purpose of a circular economy. Other sources state that this is an intrinsic part of a circular approach and should not be taken for granted.

There is also an important difference between said approaches regarding the included resources in the system. We speak here about all physical or just certain sectors, materials, products, and substances.

\subsection{Circular economy and supply chain.}

The consumption and use of materials and resources is often associated with high waste levels, despite the efficiency shown by the processes of manufacturing and freight distribution. Said consumption is heavily influenced by the supply chain, in some cases more than half is burned or discarded, whereas just ten to fifteen percent will be recycled. The cause of this is often associated with cost differences between using raw materials and recycled materials as sources. Therefore, supply chain strategies can be an important factor regarding sustainability enhancement since they can provide many more sourcing possibilities. In a circular environment, the supply chains are not so different from the ones that exist in a linear system (being, in their turn, formed by a linear sequence of supplier - manufacturer distributor - user). However, two fundamental aspects differentiate those two:

1. products are designed, built, and optimized to last longer and to be reused once their life cycle is complete. Most goods are shared (a good example being capital) which increases their utilization level. Thus, fewer resources are required to provide the same level of services.

2. The conventional linear structure that exists in a linear model becomes a feedback loop in CE. Technical goods are required to have a digital manifest, to provide information about the type, quantity, quality, which, in turn, allow for a better recycling potential evaluation. [7] 


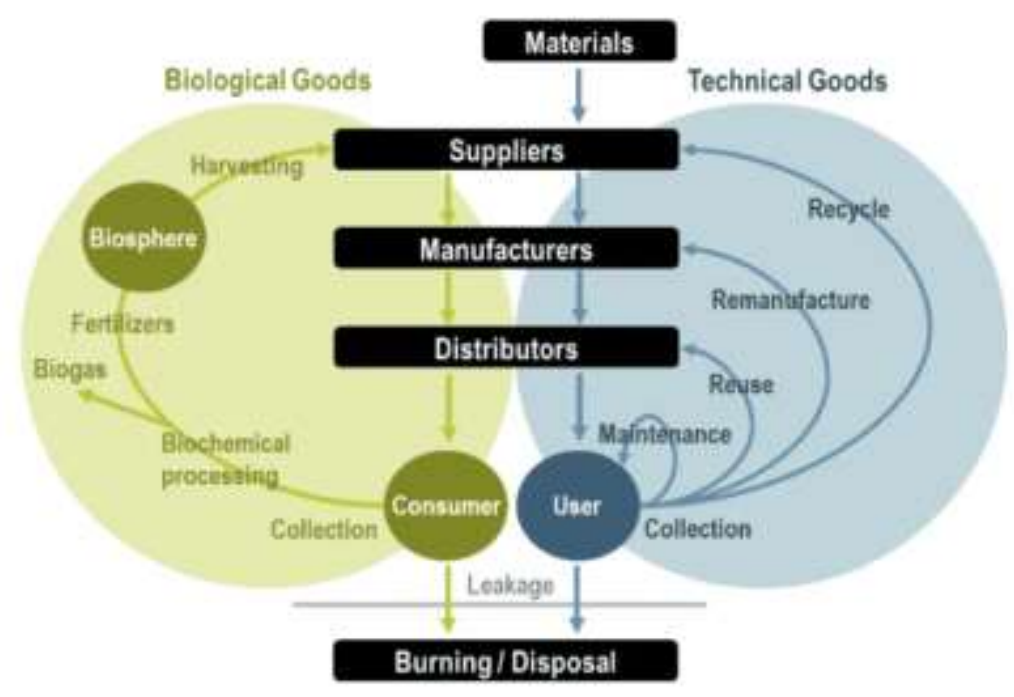

Fig. 2. Circular economy and supply chains

Source: https://transportgeography.org/contents/chapter4/transportation-sustainability-decarbonization/circular-economy-supply-chains/

Among the various implications identified in implementing the supply chain management (or SCM, in short terms), here are the most important ones:

1. Relationships among supply chains will change in circular supply chains, through shifting from product ownership to emphasize strategies based on digital systems - strategies in purchasing include a major change in a profession dominated by products and materials

2. Circular supply chains need great flexibility - buyers and suppliers will choose to collaborate via inter-connected knowledge networks

3. Both closed and open material loops must be considered in technical and biological cycles - the value must be viewed not only in terms of a reduced waste approach but also in how shorter loops and maximize the value and productivity of materials

4. Circular supply chains are enabled by close supply chain collaboration with partners within and beyond their immediate industrial boundaries $-\mathrm{CE}$ requires a conceptual shift from products and ownership to access to services.

5. Both private and public sectors' procurement policies are an important factor in the transition to a circular supply chain model if they go beyond minimum legal requirements to include the main $\mathrm{CE}$ four principles

2.3 Circular economy implementation what it means and at which levels can be achieved?

Regarding circular economy implementation, two main possibilities have been discovered in the literature:

1. it can be implemented in a systemic economy-wide perspective, for example at the regional, national, transnational, and local levels

2. it can be implemented focusing on specific groups (sectors, products, companies, markets, networks, materials, substances, various clients, and so on)

Let us discuss them one at a time. First, an economy-wide perspective has already been thought to be implemented in some countries:

- China, in which it will function on three levels: macro-scale (state, province, and city), the micro-entities or micro-scale, and the intermediate (mesoscale - a symbiosis between those two).

- The Netherlands, in which this procedure would have made from it a 'circular hotspot', so to speak. For this, numerous actions have been made: the Green Deal 
initiative (2013), the Realization Acceleration of a Circular Economy (RACE 2014) [8]

The most relevant and common example for local $\mathrm{CE}$ implementation is the industrial parks (eco-industrial), which are based on recycling and sharing resources across industries. Numerous examples of such implementation can be found in China, in Europe the one that stands out is in Denmark (The Kalundborg Park).

As for the second method, Action Plan was proposed by the EU to encourage $\mathrm{CE}$, which includes legislative actions to reduce and manage waste, to control the waste management sector, to reduce the landfilling, as well as improvements regarding producer responsibility. [9] Numerous incentives were to be imposed, as well as strong commitments on eco-design and targeted action regarding plastic, construction, food waste, consumption, fertilizers, water reuse, and so on. If we are to group the prioritized materials by their importance, the following list would be formed:

- electric and electronic equipment

- plastic, metals, paper, cardboard, glass, raw materials

- biodegradable waste

In other words, the purity of materials must represent a great denominator in this calculus. And so, the former is envisioned to be standardized, affecting the material supply on a global level.

The common CE principles identified and analyzed in the theoretical CE approaches are a must-have in the scene of the actual implementation. The majority of them heavily rely on actions and incentives that must all come from all the parts of the value chain. In other words, the CE value chain plays an important role in stock optimization. Eco-efficiency (which is defined as the minimization of the throughput using the resources) is also promoted and encouraged by said strategies and also by the four main Rs principle (reduce, reuse, recycle, repair). More than that, action within Design and Material Sourcing are also important to succeed. Nevertheless, the former is not enabled by default in a circular economic system.
Regarding the methods used for implementation, three main ideas were developed and analyzed:

- material flow analysis (MFA) - an analytical method used to quantify stocks and flows of substances, resources, material across the system [10]

- emergy analysis (EA) - emergy being the measure for the quantity of work in a biosphere driven by the solar energy

- input-output analysis (IOA) - used to analyze the impact of positive or negative economic shocks (environmental or other nature) - the most comprehensive one because it quantifies impacts across the value chain. [11]

\section{Circular economy and sustainability. 3.1 Are these two concepts that similar?}

To be able to investigate such a big research gap, two questions were specifically formulated for this matter:

1: Can you tell exactly what are the main differences and similarities between these two concepts?

2: Is the circular economy conceptually related to sustainability? If it is the case, then how is it?

To answer these two questions, bibliometric research was conducted. The latter is a wellestablished form of meta-analytical research. It takes published data, measuring text and information from different sources. All papers found were examined by using content analysis techniques. The results are as follows.

Regarding the similarities, both sustainability and circular economy are likely to emphasize intra and intergenerational changes made by the environmental hazards, as well as signaling the importance of improving, and sustaining agency and public measures upon the multiple paths that lead to development. In other words, actions that revitalize and help the environment must be made both by the public and the private sectors. The former two also share a similar perspective regarding the area of effect, relying on, promoting, and encouraging globalism. More than that, they describe the importance of diversification in accepting 
distinct opportunities regarding value creation. The cooperation between stakeholders must be not only important but imperative to succeed. To guide and standardize the behavior of stakeholders, both concepts rely on heavy regulation and incentive structures.

Table 1. Selected similarities

\begin{tabular}{|l|}
\hline \multicolumn{2}{|c|}{ Similarities between sustainability and the Circular Economy } \\
\hline - Intra and intergenerational commitments \\
- More agency for the multiple and coexisting pathways of development \\
- Integrating non-economic aspects into development \\
- System change/design and innovation at the core \\
- Multi-/interdisciplinary research field \\
- Potential cost, risk, diversification, value co-creation opportunities \\
- Cooperation of different stakeholders necessary \\
- Cenulation and incentives as core implementation tools \\
- Business model innovation as a key for industry transformation \\
- Technological solutions are important but often pose implementation problems
\end{tabular}

Source: P. N. M. E. J. Martin Geissdoerfer, "The Circular Economy-A new sustainability paradigm?" Journal of Cleaner Production, 2017.

On the other hand, it is also revealed by the specialty literature that there is an important range of differences between these two ideas. As a first example, the concepts present different roots, origins, motivations, goals, priorities, the way that they perceive responsibility, and timeframes. While the Circular Economy uses different ideas, like cradle-to-cradle and industrial ecology, sustainability is way older and was created by environmental movements and supranational bodies. With regards to the goals they pursue, as the circular economy is targeting a close loop, eliminating all resource inputs and waste and leakages of emissions of the system on which it operates, the goals of sustainability are open-ended, multiple sources attributing a considerable multitude of goals, which can also shift, depending on the considered agents and their main motives of action, their interest, if you prefer.

This can be seen also by analyzing the different motivations that drive each concept. Whereas sustainability bases its motives on past trajectories, the former being diverse and diffused and embracing adaptivity and reflexivity, the circular economy is mainly focused on making a clear distinction between linear and circular approaches regarding the usage of materials and reducing waste. Of course, promoting the latter. Sustainability aims at benefiting the environment, society as a whole, and the economy. On the other hand, a circular economy has its beneficiaries among the actors that implement the system. The environment is also seen to benefit from less depletion and pollution and society benefits from environmental improvements and certain manual actions, like manual labor or fair taxation.

Of course, different motivations mean that each one of these principles prioritise different systems, as specialty literature states. A circular economy tends to main economic systems that provide important benefits for the environment, whereas a sustainable perspective encourages all three dimensions equally and tries to put them in balance, yet it can change depending on the circumstances and contextual differences. I.e., rich countries like Sweden benefit more from policies and industrial interventions that emphasize the environment, while, at the other end of the spectrum, poor, or better said, developing countries like Zambia enjoy more social emphasis.

There is also a notable difference regarding how the two are institutionalized. Sustainability provides a comprehensive framing, being able to adapt itself to different aspirations and 
contexts, whereas, circular economy, once again, accentuates the main differences between the linear and circular approaches regarding economic processes. Let us not forget about the fact that the agency also differs. The circular economy has set a clear emphasis on companies and governments, sustainability being diffused, as the priorities should be defined by the stakeholders. Furthermore, timeframes seem to be another difference. In the case of the sustainable system, the temporal aspect is open-ended, as goals can be constantly changed or reframed over time. In contrast, CE presents theoretical limits in optimization and practical ones in implementation which can be used for a successful conclusion, geographically speaking.

At last, but not least, those two perspectives seem to perceive responsibility differently. In the sustainability area, responsibilities are not clearly defined and are formulated by multiple participants (or a group), each one not being able to think for itself and set clear boundaries regarding the former. On the other hand, literature considers the responsibility in the circular system being based on private business (public business is not encouraged in this area, because of the possible unpleasant situations it can generate), policymakers, and regulators. Sharing responsibility and information in a group is dangerous (because a decision cannot be clearly made by any of its participants), or so it seems. Moreover, the goals, commitments, and interests behind the usage of each term vary significantly. CE prioritizes financial advantages for companies, less consumption, and waste for the environment, encouraging and promoting reusability, whereas sustainability encourages the alignment between stakeholders. The next table summarizes all that was stated above in this paper. [12]

Table 2. Selected differences

\begin{tabular}{|l|l|l|}
\hline \multicolumn{2}{|c|}{ Sustainability } & \multicolumn{1}{|c|}{ Circular Economy } \\
\hline Origins of the term & $\begin{array}{l}\text { Environmental movements, non- } \\
\text { profit and intergovernmental } \\
\text { agencies, principles in silvicul- } \\
\text { ture and cooperative systems }\end{array}$ & $\begin{array}{l}\text { Different schools of thought } \\
\text { like cradle-to cradle, regula- } \\
\text { tory implementation by gov- } \\
\text { ernments, lobbying by } \\
\text { NGOs like the EMF }\end{array}$ \\
\hline Goals & $\begin{array}{l}\text { Open-ended, depending on the } \\
\text { considered agent and her interests }\end{array}$ & Closed loop \\
\hline Main motivation & $\begin{array}{l}\text { Reflexivity and adaptive -> past } \\
\text { trajectories }\end{array}$ & $\begin{array}{l}\text { Better use of the resources, } \\
\text { waste, leakage }\end{array}$ \\
\hline Prioritized system & Triple bottom line (horizontal) & The economic system \\
\hline Wide diffusion & $\begin{array}{l}\text { Providing vague framing that can } \\
\text { be adapted to different contexts } \\
\text { and aspirations }\end{array}$ & $\begin{array}{l}\text { Emphasizing economic and } \\
\text { environmental benefits }\end{array}$ \\
\hline Agency & Diffused & Governments, companies \\
\hline Timeframe of changes & Open-ended & $\begin{array}{l}\text { Theoretical limits in optimi- } \\
\text { zation and practical ones in } \\
\text { implementation }\end{array}$ \\
\hline $\begin{array}{l}\text { Perception of responsi- } \\
\text { bilities }\end{array}$ & Shared, not clearly defined & $\begin{array}{l}\text { Private business and regula- } \\
\text { tors/policymakers }\end{array}$ \\
\hline
\end{tabular}

Source: P. N. M. E. J. Martin Geissdoerfer, "The Circular Economy - A new sustainability paradigm?" Journal of Cleaner Production, 2017.

3.2 What kind of relationship types exists between?

The first relation between these two ideas is presented by describing the circularity in business models and supply chains as a precondition for generation sustainability in the manufacturing process, which, in turn, is mandatory 
and greatly affects the performance of industrialized and developing countries. In the same manner, a circular economy can be an important part of a sustainable perspective, or environment, if you want.

The second type of relationship is assumed by a different source, which mentions that circularity is necessary for sustaining economic output. A similar, almost identical approach is presenting Circular Economy as being a necessary condition for sustainably maintaining economic growth, but it takes into consideration the possibility of other pathways existing, one of them being preferable to the former.

A third type is conditional and describes service-based systems and circularity as a necessary but not efficient enough condition for sustainable systems. Other external conditions must accompany a closed-loop system to encourage sustainability in the long term. A good example of conditions will be changing lifestyles. A similar view that is good to mention is seeing circular systems as being beneficial for different sustainability dimensions like resource productivity, GDP increase, and job creation, but having one downfall: does not further say if this is enough for the system in cause, relative to other external factors, which can also influence the former and its development.

Those three stated above were positive types of relationships. Of course, between these two there are also negative types of relationships. A good example would be the necessity of putting in balance the benefits but also the costs of circular systems that must be balanced to avoid negative value generation. A similar view suggests and addresses a range of problems that the circular economy brings to the table, i.e., the technical impossibility of a closed circle in combination with growing demand or various problems that waste would generate if not managed properly. There is also the problem of the process of recycling because implementing reusability has high expenses.

The energy consumed and its impact is possible to be higher for some materials than the overall process of acquiring each one, using some conventional methods like mining and deforestation. In conclusion, the CE may worsen the gas emission and negatively impact the environment, like global warming. Therefore, pragmatic approaches must be made to avoid these consequences. The table below summarizes what was stated in this section. [13]

Table 3. Relationship types between sustainability and circular economy

\begin{tabular}{|c|c|c|}
\hline General direction & Type of relationship & Short description \\
\hline \multirow[b]{2}{*}{ Conditional } & Conditional relation & One of the main conditions \\
\hline & $\begin{array}{l}\text { Strong conditional rela- } \\
\text { tion }\end{array}$ & $\begin{array}{l}\text { The main solution for a transformation } \\
\text { to a sustainable system }\end{array}$ \\
\hline \multirow{3}{*}{ Beneficial } & $\begin{array}{l}\text { Necessary but not suffi- } \\
\text { cient }\end{array}$ & Necessary but not sufficient relation \\
\hline & Beneficial relationship & $\begin{array}{l}\text { Beneficial in terms of sustainability, } \\
\text { without alternative approaches }\end{array}$ \\
\hline & Subset relation & $\begin{array}{l}\text { One among several solutions for foster- } \\
\text { ing a sustainable system }\end{array}$ \\
\hline \multirow{3}{*}{ Trade-off } & Degree relation & $\begin{array}{c}\text { Yielding a degree of sustainability with } \\
\text { other concepts }\end{array}$ \\
\hline & $\begin{array}{l}\text { Const-benefit/trade-off } \\
\text { relation }\end{array}$ & $\begin{array}{l}\text { Having costs and benefits regarding } \\
\text { sustainability }\end{array}$ \\
\hline & Selective relation & $\begin{array}{l}\text { Fostering certain aspects of sustainabil- } \\
\text { ity but lacking others }\end{array}$ \\
\hline
\end{tabular}

Source: P. N. M. E. J. Martin Geissdoerfer, "The Circular Economy - A new sustainability paradigm?" Journal of Cleaner Production, 2017. 


\section{Conclusion}

First and foremost, based on key literature, we can conclude that the concept of circular economy can be defined as a regenerative approach in which emission, resource input, energy leakage, and emission are reduced or minimized by bringing material and energy loops to their narrowest, slowest pint ad by closing them as much as possible. This, of course, can be achieved through the four steps mentioned earlier: repairing a broken resource, remanufacturing, reusing, and recycling. Of course, the four main principles of the circular economy were defined and explained. We also delved deeper into its main levels of operations: products, networks, policies, and companies. Regarding its predecessor, the linear model, we made an antithetic comparison and tried to emphasize the benefits the CE would bring to the environment. More than that, we also stated that negative effects brought to the table by the linear economy must not be nullified to succeed in migrating from one to another.

Second of all, we define sustainability as the balanced integration of performance in the economy, social inclusiveness, and resilience in the environment, to benefit current and, why not, future generations.

This is stated because the circular economy has gained popularity and has increased research interest because of its emergence. Its roots are European, but we saw Chinese scholars who have taken up this topic, exponentially growing the number of publications in this region. To answer the first question stated in this paper - Can you tell exactly what the main differences and similarities between these two concepts (CE and sustainability) are? - the paper does exactly this: it summarizes the main similarities and differences between these two ideologies. Although these two are often used in similar contexts, the differences and similarities have not been made explicit in the literature, therefore blurring their conceptual meaning and constraining the opportunities of usage. By shedding light on their differences, the paper helps not only on the conceptual level of development, but also serves as a great tool to better reveal and understand the interests, motivations, and practical implications of their use in the public and private sectors. Moreover, the paper addressed the following question - Is Circular Economy conceptually related to sustainability? If it is the case, then how is it? It was found that the system of the circular economy represents - or it is viewed as a-condition for sustainability, a beneficial relation, or a trade-off if we are to base this affirmation on literature. This can be broken down into eight different types of relationships. The latter can be used to bring diversity and shed light on the vast range of strategies that managers and policymakers can adopt.

\section{References}

[1] W. R. Stahel, "The circular economy," 23 3 2016. [Online]. Available: https://www.nature.com/news/the-circular-economy-1.19594.

[2] C. M. Vanessa Prieto-Sandoval, "Towards a consensus on the circular economy," Journal of Cleaner Production, 2018.

[3] F. Sariatli, "Linear Economy Versus Circular Economy: A Comparative and Analyzer Study for Optimization of Economy for Sustainability," 236 2017. [Online]. Available: https://content.sciendo.com/view/journals/vjbsd/6/1/articlep31.xml.

[4] "ELLEN MACARTHUR FOUNDATION," [Online]. Available: https://www.ellenmacarthurfoundation.org/.

[5] G. o. t. Netherlands, "Opportunities for a circular economy in Netherlands," [Online]. Available: https://www.government.nl/documents/reports/2013/10/04/opportunities-for-a-circular-economy-in-the-netherlands.

[6] A. W. a. K. Skånberg, "The Circular Economy and Benefits for Society," [Online]. Available: https://www.lagazettedescommunes.com/telechargements/etude-club-rome-eng.pdf.

[7] A. f. t. E. M. Foundation, "The Circular Economy and Supply Chains," The Geography of Transport Systems, [Online]. 
Available: $\quad$ https://transportgeography.org/contents/chapter4/transportationsustainability-decarbonization/circulareconomy-supply-chains/.

[8] E. commission, "NETHERLANDS PULLS AHEAD IN CIRCULAR ECONOMY RACE," [Online]. Available: https://ec.europa.eu/environment/ecoap/about-eco-innovation/policies-matters/netherlands/netherlandspulls-ahead-in-circular-economy-race_en.

[9] E. Commission, "Single Market for Green Products Initiative," [Online]. Available: http://ec.europa.eu/environment/eussd/smgp.
[10] Wikipedia.org, "Material flow analysis," [Online]. Available: https://en.wikipedia.org/wiki/Material_flow_analysis.

[11] W. KENTON, "Input-Output Analysis," 2810 2020. [Online]. Available: https://www.investopedia.com/terms/i/input-output-analysis.asp.

[12] P. N. M. E. J. Martin Geissdoerfer, "The Circular Economy - A new sustainability paradigm?" Journal of Cleaner Production, 2017.

[13] E. M. Foundation, "Towards the circular economy - Economic and business rationale for an accelerated transition," Ellen Macarthur Foundation, 2013.

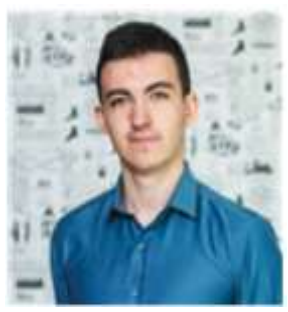

Denis-Alexandru DRAGOMIR has graduated the Faculty of Cybernetics, Statistics and Economic Informatics within the Bucharest University of Economic studies in 2018. He holds a master's degree in economics by graduating the E-Business master's program within the same faculty in 2020. In the same year he also started his doctoral studies in the field of Economic Informatics. Besides his doctoral studies, which imply the participation in national and international conferences, the publishing of articles in different journals and the participation in different scientific sessions, he currently works as a full stack software engineer at Totalsoft. His work focuses on developing, maintaining, testing software applications and making sure that the latter are of the best quality. 